\title{
SOURCE PARAMETERS ESTIMATION FROM BROADBAND REGIONAL SEISMOGRAMS FOR EARTHQUAKES IN THE AEGEAN REGION AND THE GORDA PLATE
}

\author{
Agalos A. ${ }^{1}$, Papadimitriou P. ${ }^{1}$, Voulgaris N. ${ }^{1}$, and Makropoulos K. ${ }^{1}$ \\ ${ }^{I}$ National and Kapodistrian University of Athens, Faculty of Geology and \\ Geoenvironment, Department of Geophysics and Geothermics, aagalos@geol.uoa.gr, \\ ppapadim@geol.uoa.gr,voulgaris@geol.uoa.gr,kmacrop@geol.uoa.gr
}

\begin{abstract}
Seismic moment tensors are estimated for earthquakes offshore Northern California and Greece using inversion of regionally recorded broadband seismograms. This study includes inversion results for the strongest events that occurred inside the Gorda plate and near the Mendocino triple junction from 1991 to 2005. The regional results are in good agreement with obtained teleseismic results. We finally applied the moment tensor inversion methodology and validation mainly to moderate sized earthquakes, with magnitude greater than $M=4.0$, in the Aegean area. The focal mechanisms of 131 earthquakes that occurred during the time period between June 2003 and March 2007 were estimated using this procedure.

Key words: Regional waveform modeling, moment tensor inversion, Gorda Plate.
\end{abstract}

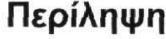

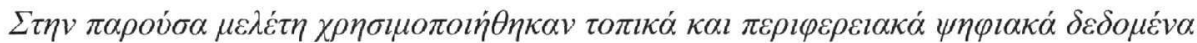

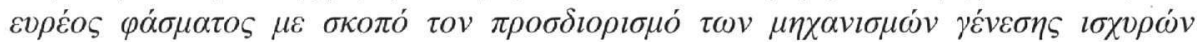

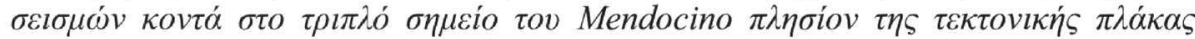

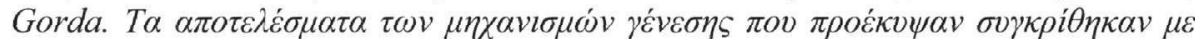

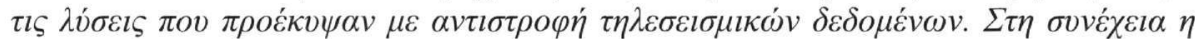

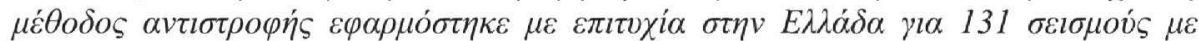

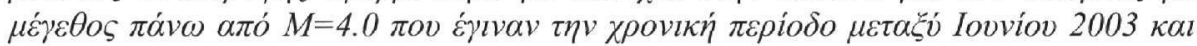
Maptiov 2007.

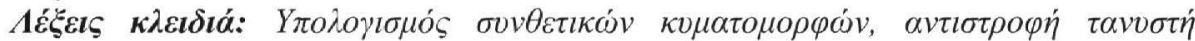

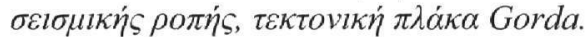

\section{Introduction}

Regional waveforms became important data to determine earthquake source parameters only recently due to the development of efficient computational tools for calculating complete waveforms in the frequency wavenumber domain. The source parameters are calculated by comparing observed and synthetic by inverting data. The synthetics are calculated using the F-K method for a given 1D earth structure. For this purpose, different codes were proposed to calculate regional synthetics (Saikia 1994, Zeng and Anderson 1995, Bouchon 2003). Fukuyama and 
Dreger (2000) and Ichinose et al. (2003), determined source parameters using regional synthetics for earthquakes in Japan and Nevada, respectively.

In this study source parameters are calculated mainly for moderate earthquakes using the F-K method proposed by Ichinose et al. (2003). The regional waveform modeling method is applied for earthquakes located in the offshore area of Northern California as well as in Greece and surrounding areas. The first area was chosen because of the high quality regional seismic broadband data from the BDSN. For this region several velocity models have shown that are adequate for long-period modeling. The station coverage of this area provides a test case with poor azimuthal coverage because most of the events studied are located offshore in the ocean or very close to the shoreline. It is important to mention that the problem with the azimuthal coverage also appears in the Aegean because a large number of events occur in the sea. For the offshore area of Northern California and the central part of the Gorda plate the largest events occurred between 1991 and 2005 and were selected in order to calculate source parameters. Teleseismic bodywave modeling was also used as a tool to compare the calculated focal mechanism solutions. Next the methodology was applied in Greece for 131 mostly moderate size earthquakes starting from June of 2003 with an end (for this paper) at March of 2007.

\section{Applied Methodology and Preparation of the data for Inversion}

In the present study synthetics for regional distances were generated using the reflectivity and frequency wavenumber summation technique proposed by Zeng and Anderson (1995). This code is based on the generalized reflection and transmission coefficient method and computes 10 fundamental green functions as it is described by Herrmann and Wang (1985). The methodology computes differential seismograms directly in a layered elastic half-space. First the medium velocity differential field is computed with respect to the velocity change in the layer and then it is multiplied with the original elastic wave field. The obtained differential waves are propagated directly to the receiver using the generalized R/T matrix method. The synthetics are calculated using the discrete wavenumber summation and imaginary frequency technique (Bouchon 1979). Then the 10 green functions are combined and produce the 3 components of motion: the tangential, radial and vertical component, as proposed by Jost and Herrmann (1989).

The obtained deviatoric moment tensor is decomposed in two parts: the Double couple component and the CLVD. Another different approach consists of the determination of the Ebest double couple solution using a grid technique where the CLVD becomes minimum. For the offshore Northern California region the WUS velocity model (Ritsema and Lay 1995) is used, while for the Aegean a velocity model including seven layers was constructed.

For the selected earthquakes we retrieved waveforms from the IRIS and ORFEUS data centers at epicentral distances of $0^{\circ}-12^{\circ}$ with good signal to noise ratio. The original waveforms used in the inversion procedure, for the earthquakes occurred in offshore of Northern California area, mostly belong to the Berkeley seismological network. For the Aegean data from stations operated by Mednet, NOA, and Geofon were used. In addition, broadband data from the three new stations Kalithea, Laka and Trizonia which are located in the western part of the Gulf of Corinth and provide data to the CRL (Bernard et al. 2006), were also used. The first two belong to the Athens University (and use Guralp CMG 40T instruments) and the third one to IPGP (France). The selection of the original waveforms was always influenced by the factor that the selected data should be able to provide the best possible azimuthally coverage needed for waveform modeling. In all the events studied we used at least two stations minimizing the effect of the uncertainty of the velocity model used along one single ray path. In many cases with good quality data more than 7 stations were used. The station identification codes, locations and instrument corrections are available on the Internet and will not be listed in this study.

The next step after the data were downloaded was the deconvolution of the instrument response from the waveforms. Next, the waveforms were integrated in order to produce pure displacement. 
The regional broad-band data were band-pass filtered in frequencies between $0.01-0.05 \mathrm{~Hz}$ for events with $\mathrm{Mw}>5.0$ and $0.02-0.05 \mathrm{~Hz}$ for events $\mathrm{Mw}<5.0$. Horizontal components were rotated to radial and transverse. The three displacement components were cut in the same starting time (nearly $10 \mathrm{sec}$ before the first arrival) with a total duration of $300 \mathrm{sec}$.

\section{Gorda Plate Tectonics}

The main tectonic characteristic of the offshore of Northern California study area is the Mendocino Triple Junction, a convergence point which is the product of the movement of three tectonic plates the North American plate, the Pacific plate and the southern part of the Juan De Fuca Plate. Gorda is the southern part of the Juan de Fuca plate. The Gorda plate is moving southeast, due to the Gorda ridge, with an average velocity of $55 \mathrm{~mm} / \mathrm{yr}$ for the last $2 \mathrm{Ma}$ and is subducted beneath the North American plate along the Cascadia thrust zone. Schwartz (1995) studied the 1992 earthquakes and referred that the southeast convergence of the Gorda Plate relative to the Pacific Plate produces a tongue of southward dipping Gorda plate beneath North America. This south-dipping section of the Gorda plate permits only a small amount of underthrusting of the Gorda plate beneath the Pacific plate. The southern edge of the Gorda plate is the oceanic Mendocino fracture zone. This zone begins at the triple point and continues in a nearly east-

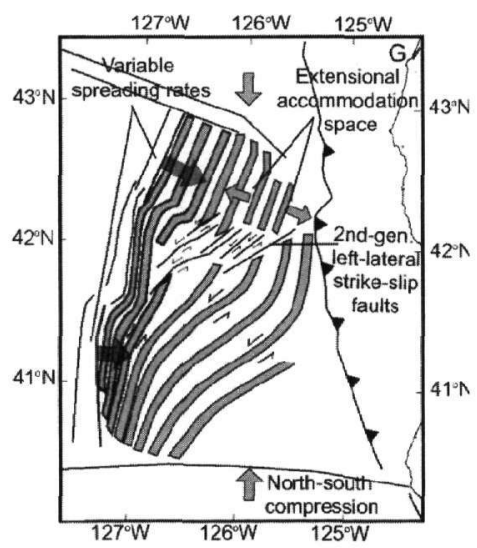

Figure 1 - Deformation model of Gorda plate based on Chaytor et al. (2004) west direction for more than $2000 \mathrm{~km}$. The Mendocino fracture zone presents the Blanco zone a dextral strike slip faulting character.

Near the Mendocino triple junction and close to the center of the Gorda plate the active deformation is expressed with intraplate left-lateral faults parallel to magnetic anomalies and spreading fabric as described by Silver (1971). Most of these left-lateral faults present a northeastsouthwest direction. Many tectonic and deformation models have proposed, in respect to Gravity and Magnetic measurements, to describe the movement of the plates in the past and to explain the present deformation. The most recent tectonic model is the one proposed by Chaytor et al. (2004), presented in figure 1. This model was defined taking into account bathymetric data, focal mechanisms and earthquake locations.

According to this model during the first stage, normal faults were created as the ridge was expanding. The crust was moving eastwards away from the ridge and during this movement the faults mainly transformed from normal to left-lateral strike slip. Under a continuous North-South compression second order left-lateral faults were created across the previously reactivated fabric. The idea of the intraplate normal faults, generated by the spreading Gorda ridge and reactivated as left-lateral is also supported by Gulick et al. (2001).

\section{Regional Waveform Inversion for the Gorda plate events}

The proposed methodology was applied for 11 events with moment magnitude larger than $\mathrm{Mw}>$ 6.0. The origin times the locations as the focal mechanism solutions are provided in table 1. In order to obtain reliable source parameters for the selected events, body-wave modeling at teleseismic distances between $30^{\circ}$ and $90^{\circ}$ was used but is not presented in this study because of limited space. The obtained results from teleseismic modeling are used as reference in comparison with the solutions provided by the regional modeling. 
The first application is the one of the 25 April 1992 event that occurred near Cape Mendocino. For the regional modeling procedure 8 stations were used. The calculated focal mechanism revealed reverse type faulting with a NW-SE direction as presented in figure 2 . The depth of the earthquake was determined at $14 \mathrm{~km}$. All the calculated parameters are presented in table 1 . The distribution of stations does not provide a good azimuthal coverage, nevertheless the calculated focal mechanism is similar to the one provided by the teleseismic modeling method. This result indicates the robustness of the method. (The small pulse presented at the tangential component at the beginning of the data of station PFO is a phenomenon that occurred because of strong filtering and is not related with the source data).
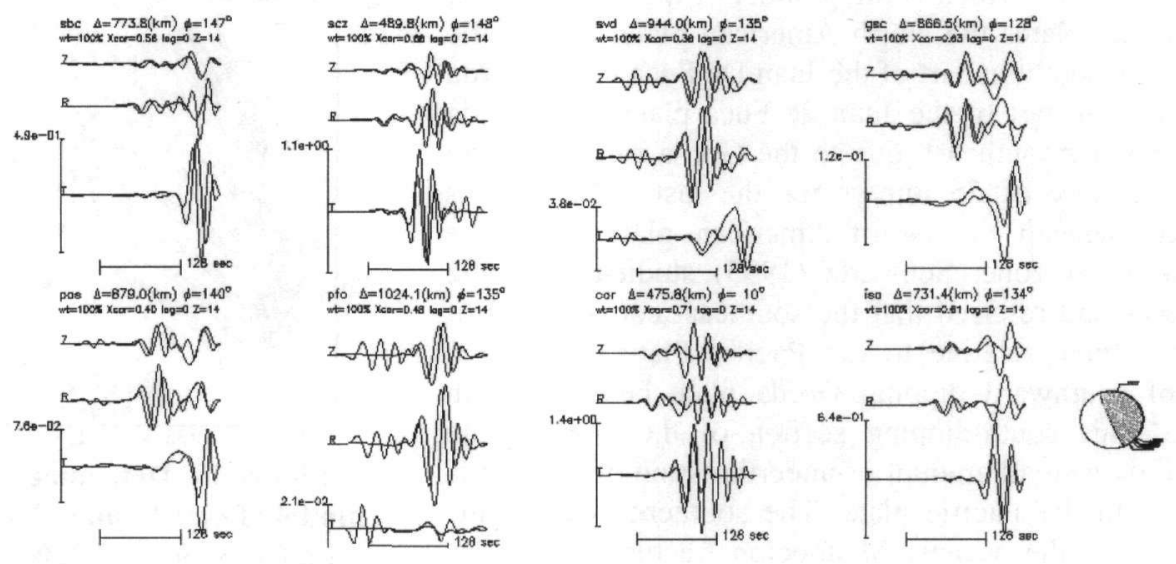

Figure 2 - Observed and Synthetics displacements of the April 251992 event and the calculated focal mechanism. In all the modeling figures with light grey color the original data are presented and with dark grey the regional synthetics

After the 25 April 1992 thrust event the next day, on 26 April 1992, two strong events occurred with similar magnitude. These events happened some decades of $\mathrm{km}$ northwestern of the thrust 4/25/1992 event at the Cape Mendocino area. For the first event 6 three component stations, while for the second one 8 stations were used. These events reveal similar strike slip faulting as it is presented in figures 3 and 4 respectively. The fault plane solutions indicate probably a NW-SE direction and the depth of the hypocenter is located at $20 \mathrm{~km}$ (Table 1).
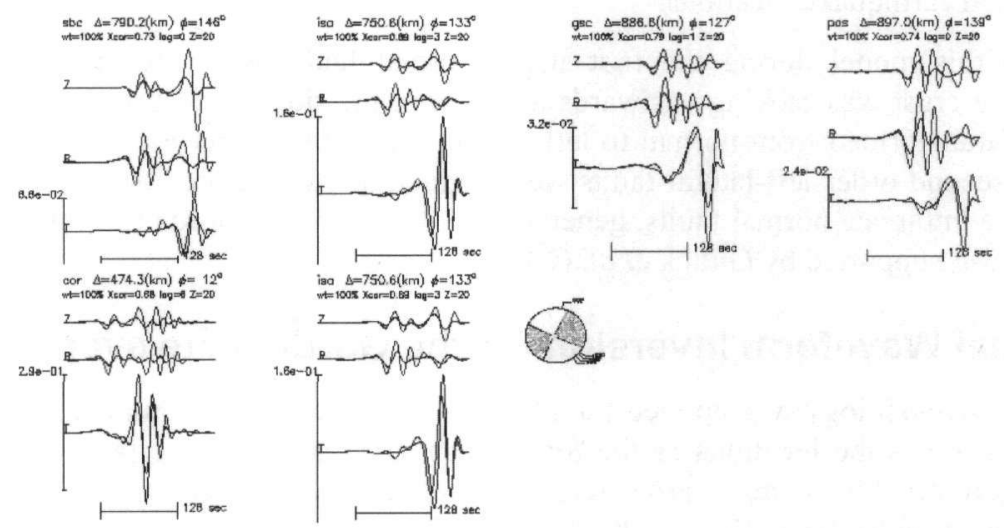

Figure 3 - Example of the analysis of the April 261992 earthquake 


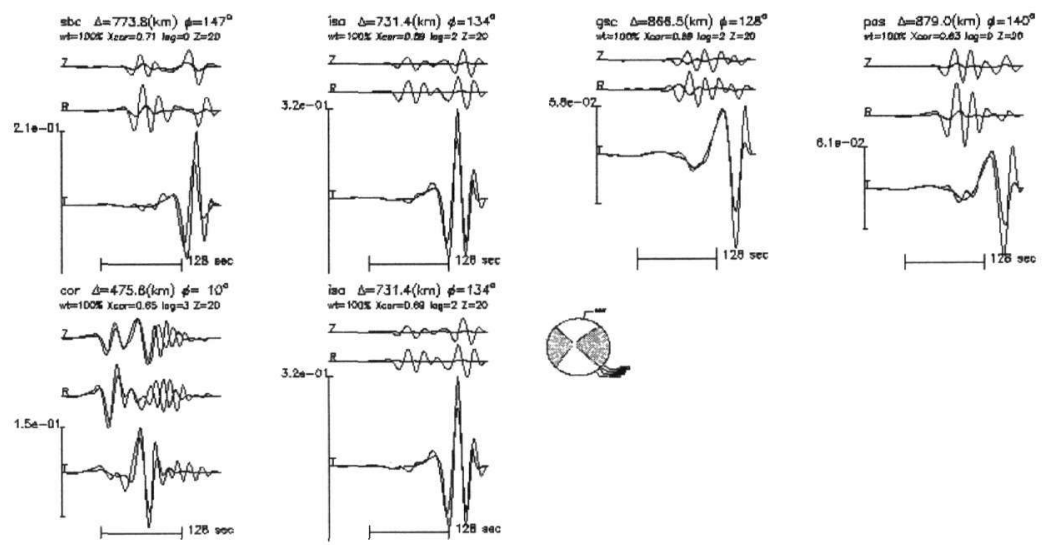

\section{Figure 4 - Observed and Synthetics displacements of the second event of April 261992 and the calculated focal mechanism}

The next significant earthquake in the study area was the event that occurred on 1 September 1994. This earthquake ruptured the central part of the Mendocino fracture zone and was modeled using 11 three component stations. The result of the modeling is presented in figure 5. The determined focal mechanism reveals dextral strike-slip type faulting. The azimuth of the fault presents an almost E-W direction in agreement with the direction of the Mendocino fracture zone. A good fit between data and synthetics is calculated and the focal depth was determined at $7 \mathrm{~km}$.

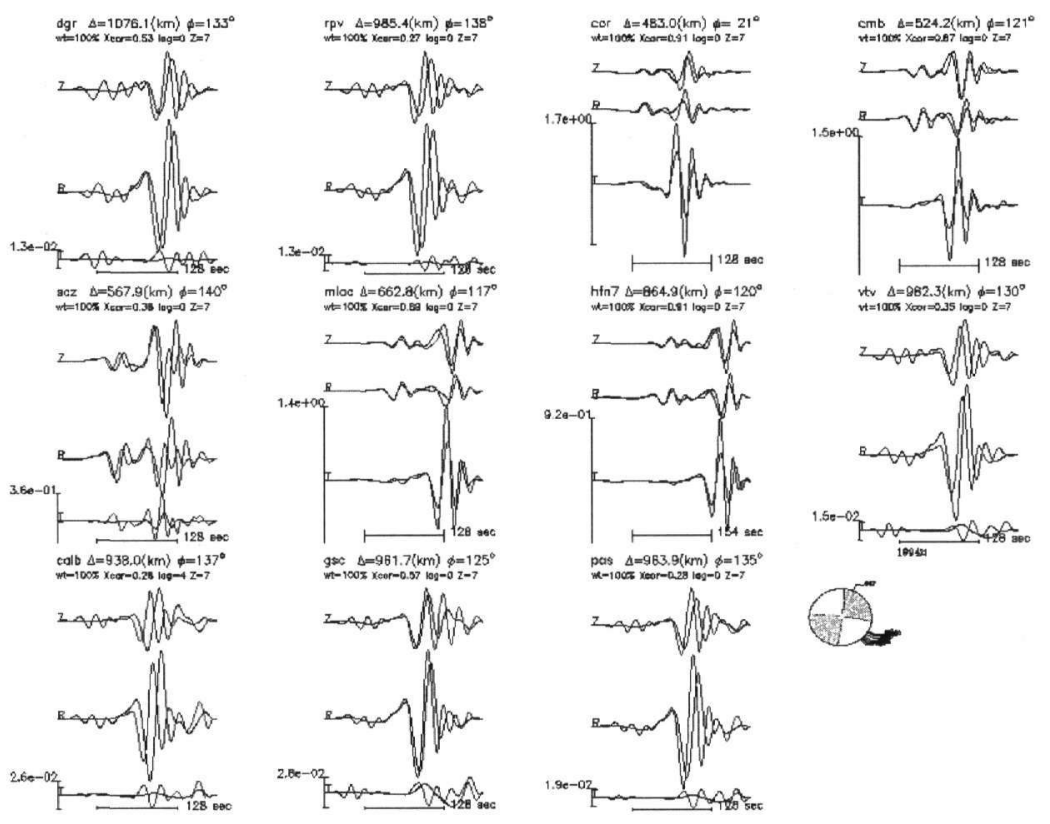

Figure 5 - Example of the analysis of the September 11994 earthquake. Fit of waveforms and focal mechanism solution are presented

On February 1995 another strong event occurred some kilometers north of the Mendocino fracture zone and close to the previous referred event. This event was modeled with 6 three component stations. Strike slip type faulting is calculated (Fig. 6) striking in NE-SW direction, while the depth of the event was determined at $20 \mathrm{~km}$. 

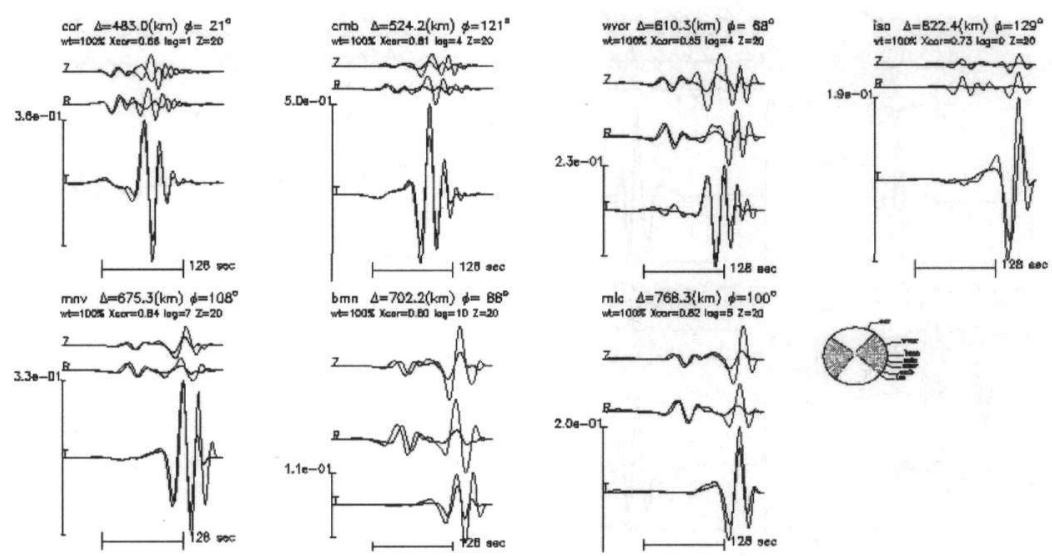

Figure 6 - Observed and Synthetics displacements of February 191995 event and the calculated focal mechanism

Table 1 - Focal mechanisms for offshore northern California events determined in this study

\begin{tabular}{|c|c|c|c|c|c|c|c|c|c|}
\hline \multicolumn{2}{|c|}{ Date } & Mw & $\begin{array}{c}\text { Lat } \\
\mathbf{( N )}\end{array}$ & $\begin{array}{c}\text { Long } \\
\mathbf{( W )}\end{array}$ & $\begin{array}{c}\text { Str. } \\
\text { Dip } \\
\text { Rake }\end{array}$ & $\begin{array}{c}\text { Depth } \\
(\mathbf{k m})\end{array}$ & $\begin{array}{c}\text { Str. } \\
\text { Dip } \\
\text { Rake }\end{array}$ & Depth (km) & $\begin{array}{c}\text { Moment } \\
\text { (Ntm) }\end{array}$ \\
\hline \multicolumn{2}{|c|}{$\mathbf{y} / \mathbf{m} / \mathbf{d}$} & & & & (Harvard) & (ISC) & This study & This study & This study \\
\hline 1 & $1991 / 7 / 13$ & 6.9 & 42.19 & 125.64 & $315 / 78 /-178$ & 11.0 & $302 / 80 /-170$ & 17 & $2.9 \mathrm{e} 19$ \\
\hline 2 & $1991 / 8 / 16$ & 6.2 & 41.72 & 125.42 & $307 / 84 / 158$ & 7.0 & $306 / 87 / 175$ & 15 & $8.7 \mathrm{e} 18$ \\
\hline 3 & $1991 / 8 / 17$ & 6.1 & 40.26 & 124.13 & $311 / 22 / 51$ & 12.0 & $312 / 25 / 57$ & 15 & $2.5 \mathrm{e} 18$ \\
\hline 4 & $1991 / 8 / 17$ & 7.0 & 41.84 & 125.41 & $314 / 62 / 176$ & 13.5 & $313 / 85 / 176$ & 14 & $3.6 \mathrm{e} 19$ \\
\hline 5 & $1992 / 4 / 25$ & 7.1 & 40.36 & 124.05 & $331 / 9 / 68$ & 15.1 & $335 / 5 / 87$ & 14 & $2.9 \mathrm{e} 19$ \\
\hline 6 & $1992 / 4 / 26$ & 6.5 & 40.51 & 124.24 & $215 / 83 / 15$ & 20.3 & $205 / 86 / 4$ & 20 & $1.0 \mathrm{e} 19$ \\
\hline 7 & $1992 / 4 / 26$ & 6.5 & 40.47 & 124.35 & $222 / 67 / 1$ & 22.2 & $225 / 77 / 2$ & 20 & $1.1 \mathrm{e} 19$ \\
\hline 8 & $1994 / 9 / 1$ & 7.0 & 40.43 & 125.69 & $274 / 65 / 176$ & 10.0 & $276 / 88 / 176$ & 7 & $4.5 \mathrm{e} 19$ \\
\hline 9 & $1995 / 2 / 19$ & 6.6 & 40.56 & 125.53 & $307 / 72 /-177$ & 10.0 & $309 / 86 /-175$ & 20 & $1.3 \mathrm{e} 19$ \\
\hline 10 & $2005 / 6 / 15$ & 7.2 & 41.30 & 125.97 & $225 / 85 / 13$ & 10.0 & $227 / 80 / 4$ & 11 & $3.5 \mathrm{e} 19$ \\
\hline 11 & $2005 / 6 / 17$ & 6.7 & 40.77 & 126.57 & $197 / 80 / 10$ & 10.0 & $194 / 80 / 8$ & 10 & $2.0 \mathrm{e} 19$ \\
\hline
\end{tabular}

The epicenters of the 1994 and 1995 events are quite close nevertheless they revealed different type of faulting. This happens as the left-lateral strike slip faults nearly reach the right-lateral strike slip fracture zone of Mendocino which has an almost East-West direction. The direction of faulting for the left-lateral faults is nearly Northeast-southwest for the events at the center of the Gorda plate and is changing nearly to North-south near the Mendocino fracture zone, a fact well explained by the deformation model shown in figure 1 .

The last two strong earthquakes that occurred in the study area are the ones of 15 and 17 June of 2005. The first event was modeled with 10 stations. The focal mechanism revealed strike-slip focal mechanism as shown in figure 7, with a NE-SW direction. The depth of the hypocenter was determined at $11 \mathrm{~km}$. 

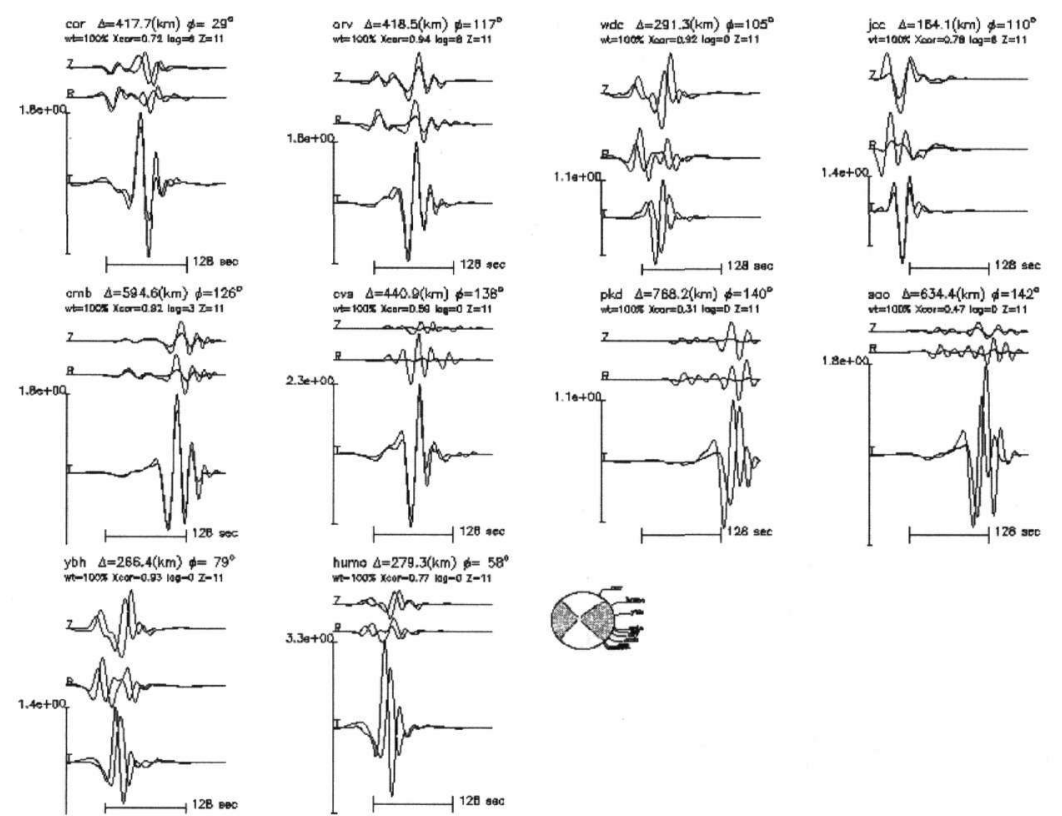

Figure 7 - Example of the analysis of the June 152005 earthquake. Fit of waveforms and focal mechanism solution are presented

On 17 June 2005 an event occurred approximately $40 \mathrm{~km}$ southern from the previous event. This event was also modeled with 10 stations. The calculated fault plane solution represents a leftlateral strike slip type faulting. The direction of the fault plane is $194^{\circ}$ and the depth was estimated at $10 \mathrm{~km}$ (Fig. 8).
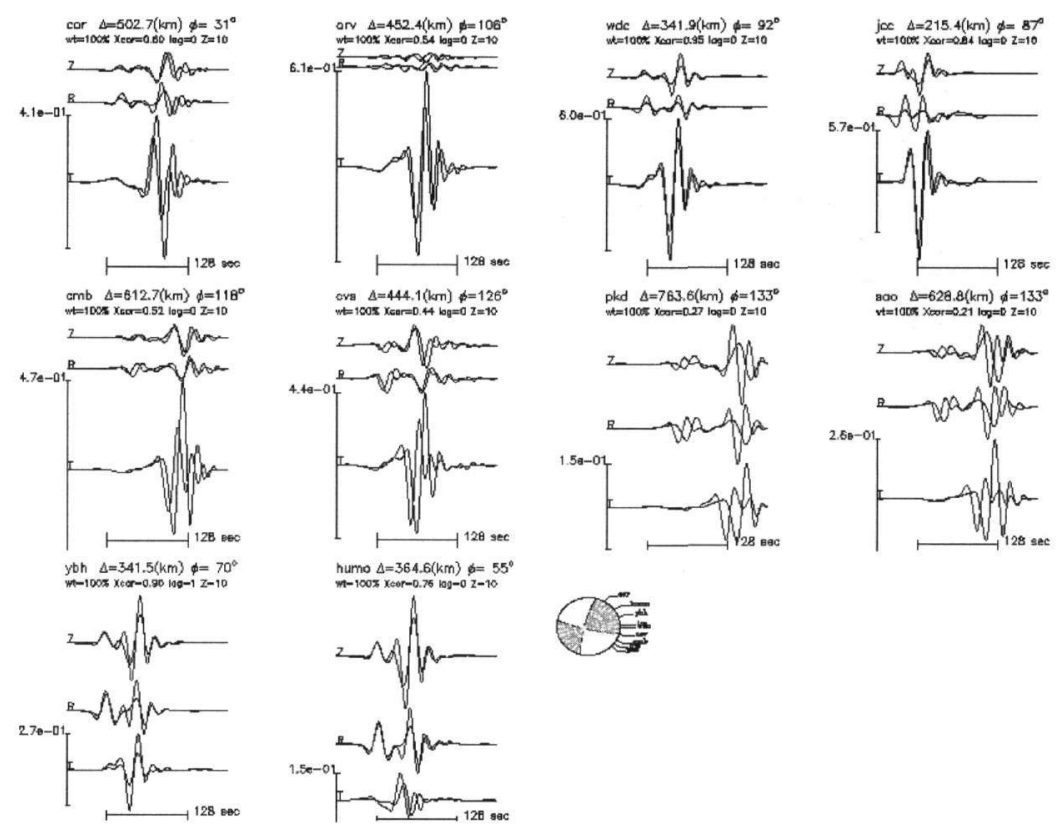

Figure 8-Observed and Synthetics displacements of June 172005 event and the calculated focal mechanism 
The conclusion from the 11 strong events that were studied is that the source parameters calculated using the proposed methodology were well determined in comparison with the solutions estimated using teleseismic modeling as well as with those proposed by Harvard. Because of limited space the bodywave modeling in teleseismic distances and 4 from 11 regional modeling results were not presented. All the focal mechanisms obtained revealed for the largest events for the region offshore of Northern California between 1991 and 2005 are presented at figure 9 . The 11 greatest events of that period which were selected for waveform modeling mostly indicate ruptures of strike slip faults. Additionally thrust faulting was revealed. The calculated thrust type faulting is related with two events which occurred close to Cape Mendocino and are related with the Cascadia subduction zone. The study of the event occurred on September 1994 revealed dextral strike slip focal mechanism and can be related with the Mendocino fracture zone.

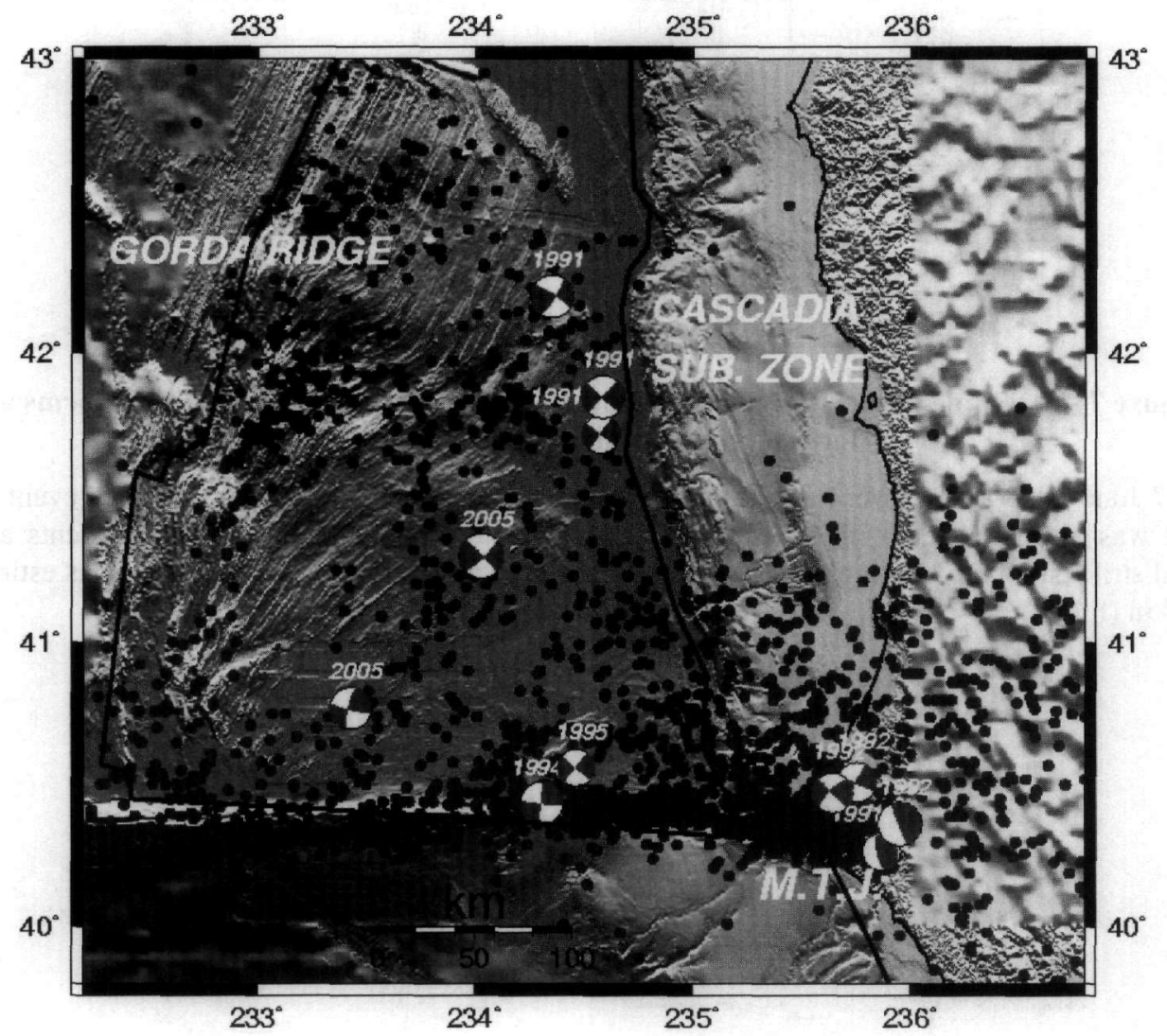

Figure 9 - The focal mechanisms determined in this study and the earthquakes with magnitude $M>3$ for the last 30 years

\section{Earthquakes Modeled in Greece}

The Aegean is characterized by a complex deformation pattern. One of the major fracture zones is the one of the Hellenic trench, where mainly thrust faulting is observed, as it is the area where the African and European plates are converged. The northern part is dominated by the right lateral strike slip north Anatolian fault while the central part is deformed by normal faults striking in an almost E-W direction. Generally the seismicity of Greece is characterized by an important number of intermediate size earthquakes in different depths and various type faulting.

In this study source parameters were calculated for 131 moderate size earthquakes that occurred during the time period from June 2003 to March of 2007 (time period of available recordings for 
moderate events). The characteristics of tectonic complexity described above must be revealed by the focal mechanisms as well as by focal depth. In this study 3 events will be presented but the whole catalogue and all the waveform modeling figures are available on line through the www.geophysics.geol.uoa.gr site.

The 8 January 2006 event, located near Kythera Island at southern Greece, was the strongest event in the region since 1903 . The area is mainly characterized by thrust faults whose directions lie nearly perpendicular to the Hellenic Arc. The last strong earthquake that occurred in this region was the one of August 1903 but with bigger magnitude (Papadopoulos and Vassilopoulou 2001). Although the 2006 event was very strong and was felt nearly at whole Greece the damages were not so big because it was a deep event. Nearly all the damage found at the central part of the Kythera Island was mainly expressed with collapses of old masonry buildings and some secondary geodynamic effects as rock-falls and landslides. The source parameters of this event were obtained using broadband data from 103 component stations with a good azimuthal coverage. The fit between data and synthetics is presented in figure 10. The waveform modeling procedure revealed magnitude $\mathrm{Mw}=6.5$ and the focal depth was estimated at $64 \mathrm{~km}$.

The next selected event is the one that occurred near the Skyros Island on 21 February 2006 with a magnitude $\mathrm{Mw}=4.5$. This event occurred close to the 2001 mainshock, located NW of the island with magnitude $\mathrm{Mw}=6.5$ (Roumelioti et al. 2003, Ganas et al. 2005). Eight three component broadband stations were used with low amplitudes of noise to model this event (Fig. 11). The regional modeling technique revealed left-lateral strike slip type faulting in a northwest - southeast direction. The hypocenter depth was estimated at $16 \mathrm{~km}$. The revealed fault plane direction was similar with the one determined for the 2001 event.

Several seismotectonic studies present that in the Gulf of Corinth a large number of small events occur every year, showing that the Gulf is an active tectonic rift opening in an almost N-S direction. One event was studied with the regional moment tensor inversion procedure. This is an example used to show the possibility to calculate the source parameters of small events at local distances. The selected event occurred on 9/12/2006 and was recorded by the recently installed broadband stations Trizonia (918C), Kalithea (922A) and Laka (922D). The small magnitude of the selected event does not allow a good fitting, due to the pure azimuthal coverage and to the high level noise. However, the obtained focal mechanism is in agreement with the fault plane solutions of other events that occurred in the same area. The original waveforms and the synthetics are presented in figure 12. The vertical component was not well modeled at Trizonia and Kalithea, because of the high level noise. The focal mechanism revealed normal type faulting with an E-W fault plane direction which is a very common focal mechanism solution for this region, as presented by the seismotectonic studies of Agalos and Lentas (2004) and Bernard et al. (2006).

The epicenters of the 131 studied events (Fig. 13) are mainly concentrated in four regions. The first one covers the Ionian Islands. The focal mechanisms at the western part of the Kefallinia Island are related with right lateral strike slip type faulting and those southern of Lefkada Island with thrust type faulting. The second region where an important number of events was located is the one between South Peloponnesus and Western Crete, while the third is between Eastern Crete and Rhodes Island. The complex deformation of this area is represented by various type faulting. Namely, southwestern of Crete thrust type faulting mainly appears, while most of the events that occurred in the eastern part of Crete are related with strike slip faulting. The fourth region extends from Northern Rhodes to the western coast of Turkey. Focal mechanisms northern of Rhodes present normal type faulting, whereas in the western part of Turkey strike slip type faulting, probably related to the branches of the North Anatolian Fault. 


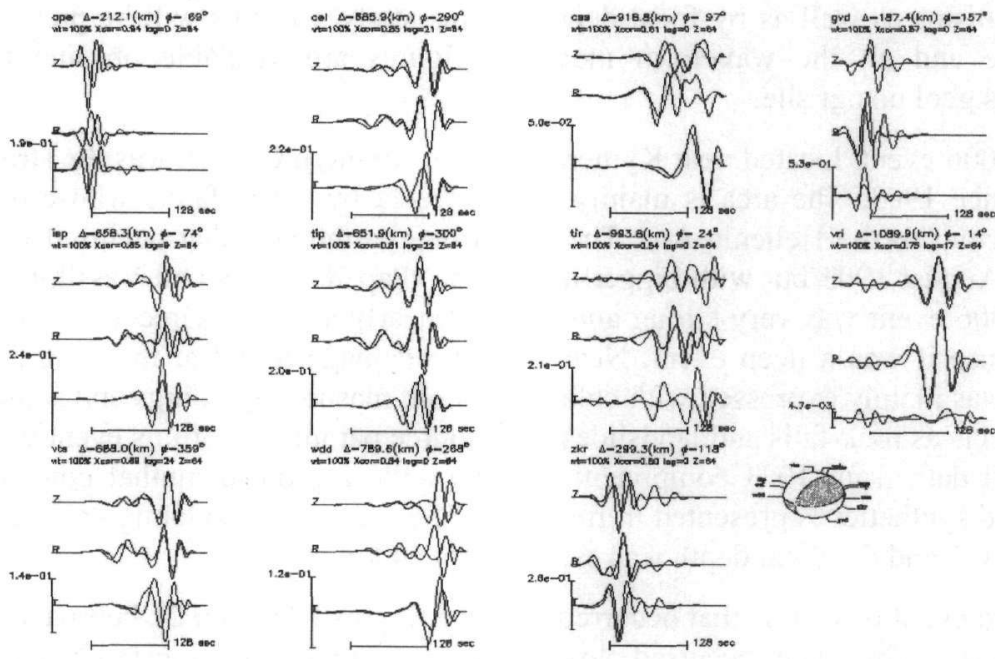

Figure 10 - Regional inversion result for the January 82006 Kythera mainshock
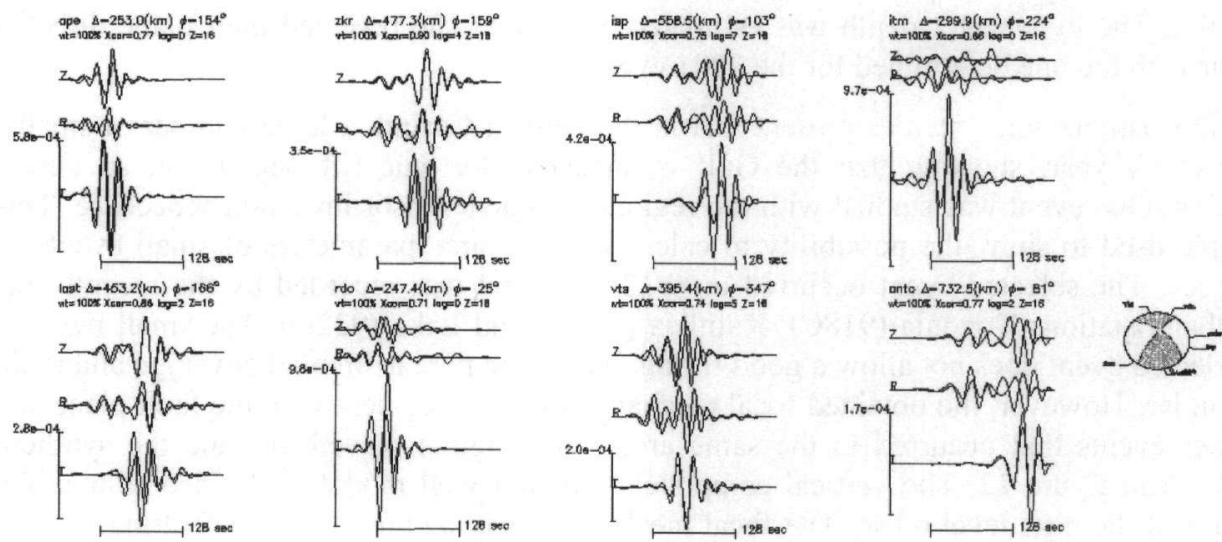

Figure 11 - Focal mechanism solution retrieved for the February 212006 event near the Skyros Island
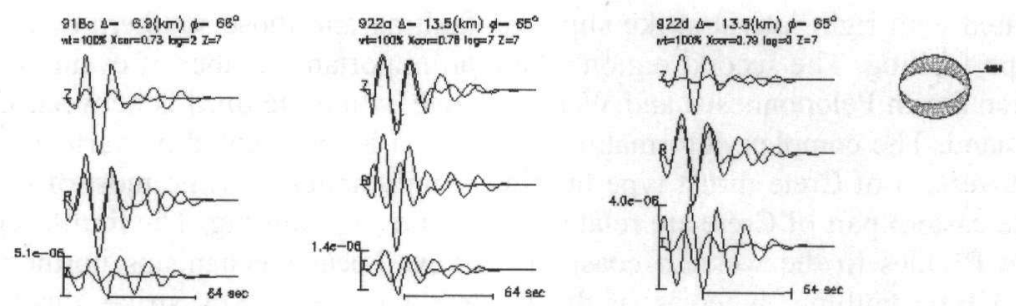

Figure 12 - Example of the source parameters analysis of the September 122006 earthquake with local observed waveforms. Fit of waveforms and focal mechanism solution are presented 


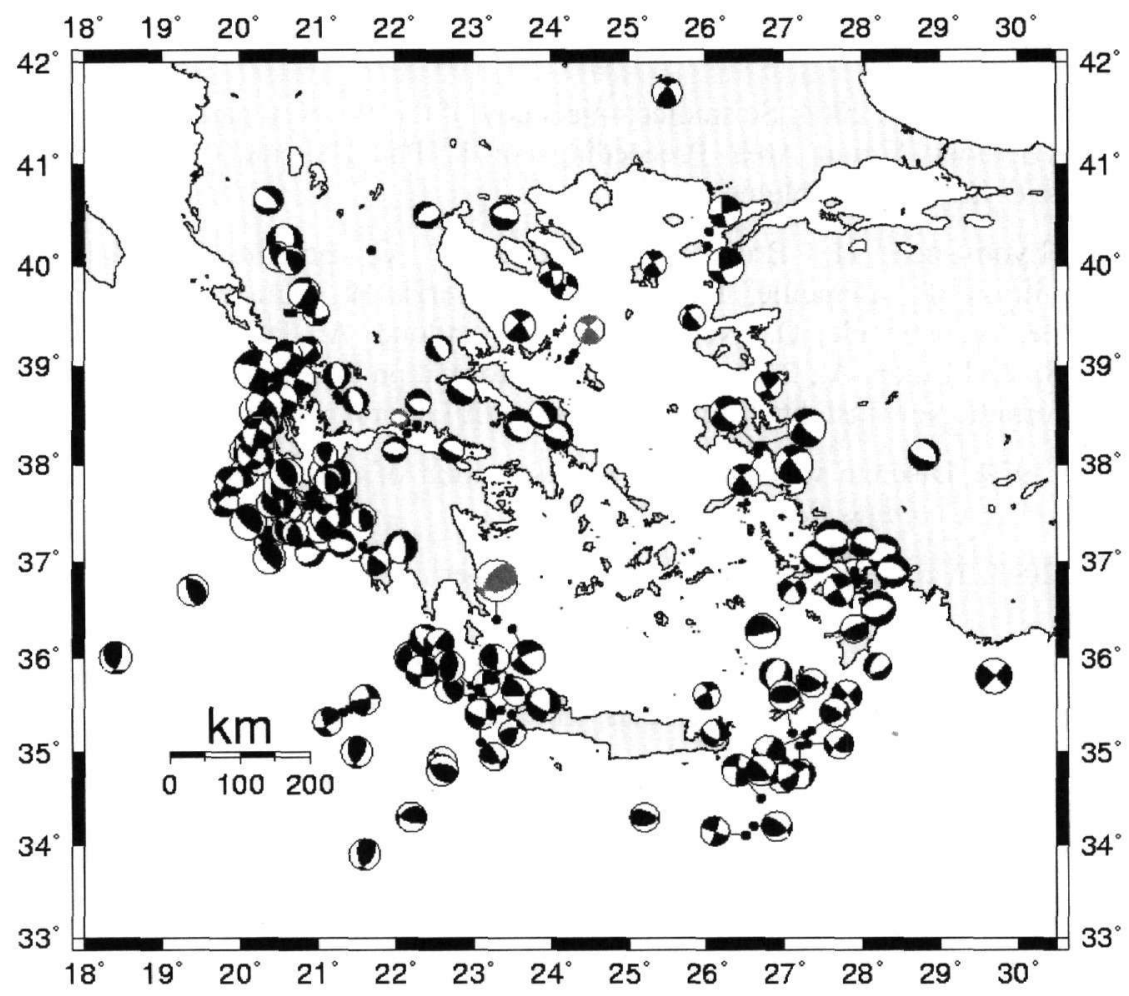

Figure 13 - 131 Focal mechanisms solutions determined in this study between June 2003 and March 2007. With grey color the focal mechanisms for the three events presented, black for all the other estimated solutions

\section{Conclusions}

In this study the presented source parameters are obtained from the waveform modeling of regional broadband data. The moment tensor inversion method was applied for earthquakes that occurred a) in the region offshore of Northern California and the Gorda plate and b) in several regions of Greece. For the first study region 11 strong events were selected and the results from the regional modeling indicated that our solutions are similar with those generated using the teleseismic modeling technique, as well as with those proposed by Harvard. The method was first successfully applied in the Gorda region (USA) and later applied mostly for moderate size earthquakes occurred in Greece and surrounding area during June 2003 and March 2007. In the last case 131 events were analyzed and their source paremeters were calculated. The method was applied for a large variety of magnitudes and could determine the fault plane orientation and seismic moment even under conditions of poor azimuthal coverage, as the fit of data and synthetics was well predicted for most events.

\section{Acknowledgments}

We would like to thank G. Ichinose for providing the regional inversion codes and Y. Zeng and J. G. Anderson for providing the F-K code to compute the regional synthetics. 


\section{References}

Agalos, A., and Lentas, C., 2004. Seismotectonic study of the Western part of the Gulf of Corinth and the broader Aigion Area, Proceedings of $1^{\text {st }}$ Pan Hellenic Conference of Geology Students, GAIA, No 14 Volume A, 1-12.

Bernard, P., Lyon-Caen, H., Briole, P., Deschamps, A., Boudin, F., Makropoulos, K., Papadimitriou, P., Lemeille, F., Patau, G., Billiris, H., Paradissis, D., Papazissi, K., Castarède, H., Charade, O., Nercessian, A., Avallone, A., Pacchiani, F., Zahradnik, J., Sacks, S., and Linde, A., 2006. Seismicity, deformation and seismic hazard in the western rift of Corinth: New insights from the Corinth Rift Laboratory (CRL), Tectonophysics.

Bouchon, M., 1979. Discrete wave number representation of elastic wave fields in three-space dimension, J. Geophys. Res. 84, 3609-3614.

Bouchon, M., 2003. A review of the discrete wavenumber method, Pure appl. geophys. 160, 445465.

Chaytor, J.D., Goldfinger, C., Dziak, D.P., and Fox, C.G., 2004. Active deformation of the Gorda plate: constraining deformation models with new geophysical data, Geology, 32, 4, 353356.

Fukuyama, Eiichi, and Dreger, D.S., 2000. Performance test of an automated moment tensor determination system for the future "Tokai" earthquake, Earth Planets Space, 52, 383-392.

Ganas, A., Drakatos, G., Pavlides, S. B., Stavrakakis, G. N, Ziazia, M., Sokos, E., and Karastathis, V.K., 2005. The $2001 \mathrm{Mw}=6.4$ Skyros earthquake, conjugate strike-slip faulting and spatial variation in stress within the central Aegean Sea, Journal of Geodynamics, 39, 6177.

Gulick, S.P., Meltzer, A.S., Henstock, T.J., and Levander, A., 2001. Internal deformation of the southern Gorda Plate: fragmentation of a weak plate near the Mendocino triple junction, Geology, 29, 8, 691-694.

Herrmann, T., and Wang, G. Y., 1985. A comparison of synthetic seismograms, BSSA, 75, 41-56.

Ichinose, Gene A., Anderson, John G., Smith, Ken D., and Zeng, Yuehua, 2003. Source parameters of Eastern California and Western Nevada Earthquakes from regional moment tensor inversion, BSSA, 93, 61-84.

Jost, M. L., and Herrmann, R., 1989. A student's guide to and review of moment tensors, Seism. Res. Lett., 60, 37-57.

Papadopoulos, G. A., and Vassilopoulou, A., 2001. Historical and archaeological evidence of earthquakes and tsunamis felt in the Kythira strait, Greece. Tsunami Research at the End of a Critical Decade, 119-138pp.

Ritsema, J., and Lay, T., 1995. Long period regional wave moment tensor inversion for earthquakes in the western United States, J. Geophys. Res,. 100, 9853-9864.

Roumelioti, Z., Kiratzi, A., and Melis, N., 2003. Relocation of the 26 July 2001 Skyros island (Greece) earthquake sequence using the double-difference technique, Physics of the Earth and Planetary Interiors, 138, 231-239.

Saikia, C. K., 1994. Modified frequency-wavenumber algorithm for regional seismograms using Filon's quadrature, modelling of Lg waves in eastern North America, Geophys. J. Int. 118, $142-158$. 
Schwartz, S. Y., 1995. Source parameters of aftershocks of the 1991 Costa Rica and 1992 Cape Mendocino, California, earthquakes from inversion of local ampliude ratios and broadband waveforms, BSSA, 85, 6, 1560-1575.

Silver, E. A., 1971. Tectonics of the Mendocino triple junction, Geol. Soc. Am. Bull., 82, $2965-$ 2978.

Zeng, Y., and Anderson, J. G., 1995. A method for direct computation of the differential seismogram with respect to the velocity change in a layered elastic solid, BSSA, 85, 300307. 